\title{
CONFLiCTOS SOCIALES Y POLÍTICOS Y SU JUDICIALIZACIÓN EN UNA COMUNidAd ANDina, NORTE DE CHILE (1867-1925)
}

\author{
Carlos Choque Mariño
}

\section{* Introducción}

Resumen

El siguiente artículo evidencia los diversos conflictos jurídicos que se produjeron desde fines del siglo XIX al XX, en la comunidad andina de Socoroma. Se busca con ello, la identificación y comprensión de las rupturas, problemas y judicialización de las controversias comunitarias y los cambios ideológicos, que emergieron en el contexto de la controversia por las provincias de Tacna y Arica (1883-1929). Asimismo, se busca analizar cómo la población indígena logró interactuar con los sistemas normativos y judiciales del gobierno chileno y peruano, con la finalidad de resolver los pleitos individuales y comunales, utilizando documentos legales coloniales y republicanos.

Palabras claves: comunidad indígena - pleitos judiciales - Arica norte de Chile.

The following article presents a number of legal conflicts that occurred in the late nineteenth and twentieth centuries in the Andean community

of Socoroma. The aim is thus the identification and understanding of

the disruptions, problems and prosecution of community disputes and ideological changes that emerged in the context of the controversy over the provinces of Tacna and Arica (1883-1929). This article also seeks to explore how indigenous people managed to interact with the regulatory and judicial systems of the Chilean and Peruvian government to resolve individual and communal strife using colonial and republican legal documents.

Key words: indigenous community - lawsuits - Arica northern Chile.

Recibido: Diciembre 2013. Aceptado: Marzo 2015
Las primeras décadas del siglo XIX trajeron consigo una serie de modificaciones sociales, económicas y políticas para las sociedades hispanoindígenas de los Andes. Al complejo proceso independentista del Perú, le sigue un largo período de conflictos civiles e internacionales y de ensayos constitucionales promovidos por conservadores, federalistas y liberales, triunfando finalmente los últimos con la imposición de la constitución liberal de 1867. Asimismo, se definen los mecanismos de interacción y participación de los nuevos ciudadanos, pero la continuidad de los prejuicios coloniales impide una integración política efectiva de toda la población indígena, ello a pesar de claras motivaciones de los artículos $38^{\circ}$ y $39^{\circ}$ de la constitución de $1867^{2}$, en lo referido a la ciudadanía. Sin embargo, en los planos administrativos, económicos y judiciales, la población indígena hace pleno uso de los instrumentos estatales disponibles, ello antes y después de la guerra del Pacífico (Choque 2012, 2013; Díaz y Tapia 2013).

Diversos estudios revelan las tempranas aproximaciones y utilización de los sistemas jurídicos hispanos y republicanos por las poblaciones indígenas, tal como evidencian Trelles (1991), Hidalgo (2004), Aguilar y Cisternas (2007), Choque (2009, 2013) y Moragas, Aguilar y Araya (2010), entre algunos investigadores. Las temáticas abordadas en dichos tribunales correspondieron a: litigios por tierras, reconocimiento de paternidad, pleitos por testamentos y contratos, cuyo uso, según Jeremy Munford (2008), se intensifica a medida que la población andina absorbió los discursos y prácticas de las instituciones coloniales, generándose con ello una

1 Departamento de Ciencias Históricas y Geográficas, Facultad de Educación y Humanidades, Universidad de Tarapacá. Av. 18 de Septiembre 2222 , Casilla 6D, Arica, CHILE. Email: cochoquem@uta.cl

2 Tempranamente la constitución de 1822 estableció el derecho a sufragio siempre y cuando se supiese leer y escribir, se fuese mayor de edad y casado. 
perpetuación del modelo de dominación ideológica, que luego se extendería al período republicano (Fuenzalida et al. 1970; Millones 2004; Castro y Rivera 2011) 3 .

En consecuencia, la práctica de la litigación forma parte del corpus e interacciones sociales en los Andes Meridionales, llevando a la élite indígena a detentar una presencia activa en los tribunales locales (Inostroza 2011; Choque 2013)4. Socoroma, una comunidad localizada a $3200 \mathrm{msnm}$ y a $120 \mathrm{~km}$ de Arica ${ }^{5}$, cuyos paisajes se caracterizan por diversos accidentes orográficos, cerros y quebradas, no estuvo exenta de los cambios políticos y administrativos producidos por la ocupación chilena de Arica y Tacna (1883-1929) luego de firmado el tratado de Ancón (Choque 2013) ${ }^{6}$. Pues, dicho pacto no impide que los indígenas utilicen el sistema judicial chileno, aplicado mediante la ley 2.261, en octubre del año 1884 (Galdames et al. 1981; Castro 2008). Entonces, icómo se expresaron las figuras de víctimas, infractores y testigos en la comisión de eventuales delitos en la comunidad de Socoroma a fines del siglo XIX e inicios del XX?, ¿qué interpretaciones sociales, morales y étnicas se expresan en los procesos judiciales desde la perspectiva de las autoridades chilenas y los comuneros andinos?, y icuáles son las expresiones del ethos cultural y la praxis jurídica de la

3 Estableciendo un riguroso análisis de la realidad peruana, Luis Millones señaló que ser indio en el Perú nunca ha sido fácil. Ya que mediante el exterminio físico o cultural, los códigos sociales y los estereotipos construidos desde los sectores hegemónicos, se ha intentado "invisibilizar" al indio. Por tal razón, los indígenas nunca serían incorporados a la república como ciudadanos de primera, pues la raza indígena era inferior a la criolla y mestiza.

4 La existencia de la élite indígena en los Altos de Arica está ampliamente documentada en numerosos trabajos que evidencian la existencia de alcaldes indígenas en los cabildos, y luego la aparición de los tenientes gobernadores y subdelegados en el Perú republicano del siglo XIX.

5 Socoroma está localizada en la provincia de Parinacota, extremo norte de Chile.

6 Este tratado en su artículo $\mathrm{N}^{\circ} 3$ expresa que "el territorio de las provincias de Tacna y Arica que limita, por el Norte, con el río Sama, desde su nacimiento en las cordilleras limítrofes con Bolivia hasta su desembocadura en el mar, por el Sur, con la quebrada y el río de Camarones, por el Oriente, con la República de Bolivia; y por el poniente con el mar Pacífico, continuara poseído por Chile y sujeto a la legislación y autoridades chilenas durante el termino de diez años [...]" (Ministerio de Relaciones Exteriores del Perú, 1928, pp. 4-5). población indígena frente a los conflictos ideológicos que se manifestaron en los pleitos judiciales?

Las evidencias documentales descubiertas nos permiten identificar una diversidad de discursos, lenguajes y articulaciones socioculturales y políticas frente a la comunidad y Estado (Méndez 2011), hecho observado tempranamente en el Perú decimonónico por Cristóbal Aljovín de Losada (2005) y que tiene idénticas similitudes con las causas civiles y criminales que se trataron bajo la administración chilena (Ruz y Díaz 2011; Choque 2012). En este contexto, la hipótesis tiene en consideración el siguiente enunciado, la elite indígena y los vecinos de Socoroma desarrollaron diversas estrategias culturales y políticas para enfrentar los procesos judiciales, tanto con actores locales y foráneos, desplegando para ello roles subalternos o hegemónicos, teniendo además, un efectivo discurso y una dramatización narrativa que les permite tener una coherencia cultural e ideológica al interior de la comunidad hasta mediados de la década de 1920. Por tal razón, nuestro objetivo es comprender como se manifiestan al interior de la comunidad los conflictos económicos, sociales y políticos, y el proceso de judicialización que sufrieron en el contexto de la chilenización de Tacna y Arica, así como también las estrategias culturales que se divisan en los pleitos estudiados, que finalmente contribuirían a los cambios culturales en dicha comunidad (Figura 1).

\section{* Los socoromeños en el sistema judicial CHILENO. VÍ́CTIMAS, IMPUTADOS Y TESTIGOS}

La constitución peruana de 1867, en su artículo $33^{\circ}$, establece que: "son peruanos por nacimiento, aquellas personas que nacen en la república"7. En sus artículos siguientes, señala que todo peruano está obligado a servir a la república con su persona y bienes. En lo relativo a la ciudadanía, el artículo $38^{\circ}$ agrega que son ciudadanos peruanos en ejercicio aquellas personas mayores de 21 años y los emancipados. En el caso Chile, la constitución de 1833 se basa en los principios del ius soli y ius sanguinis, y respecto a la ciudadanía, el artículo $8^{\circ}$ instaura que son chilenos quienes hayan cumplido 25 años, si son solteros, y 21 si son casados, además de saber leer y escribir y poseer a su vez propiedades inmuebles, oficios y rentas acreditadas, solo ellos poseerán la ciudadanía chilena. Es decir, ambas constituciones poseen las mismas orienta- 


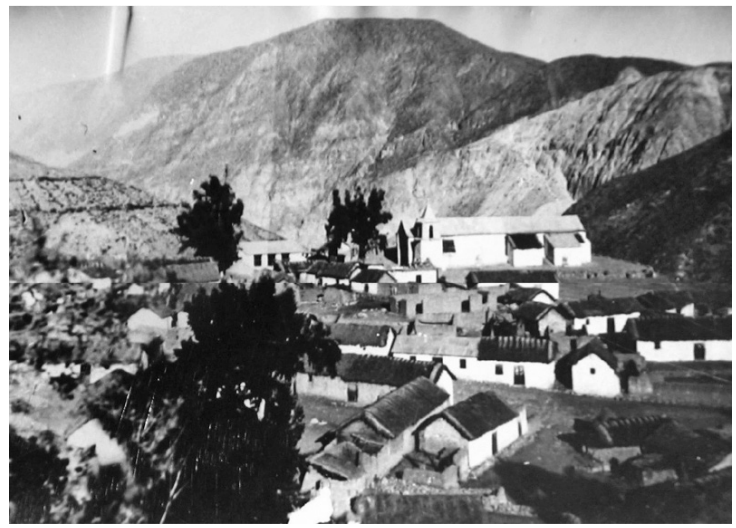

Figura 1. Socoroma en la década de 1940 (Fuente: Archivo de Juan Benavides).

ciones jurídicas que evolucionaron de la constitución española de 1812, pues cada constitución rescata aspectos del andamiaje constitucional de Cádiz (Tateishi 2008; Westermeyer 2012), que luego reflejarían en sus legislaciones y jurisprudencia.

Si bien las constituciones del Perú y Chile, respectivamente, contemplaron la existencia de la igualdad de derechos, la sobrevivencia de las calificaciones y estereotipos coloniales, impidieron la práctica efectiva de la ciudadanía y también del derecho. Dichas contradicciones se mantuvieron hasta la aplicación de la constitución de 1867, pues a partir de ella, los indígenas del Perú pudieron ejercer sus derechos ciudadanos y generar el fortalecimiento de las élites locales (Ruz 2008; Díaz et al. 2011) ${ }^{8}$. El resultado de las innovaciones jurídicas produce una élite indígena muy activa en los asuntos políticos de las provincias de Arica y Tacna. El advenimiento de la gue-

7 En los artículos posteriores de la constitución se presentan otros tipos, condiciones y derechos de naturalización.

8 Fernando Fuenzalida señaló, en este aspecto, que el Perú está constituido por tres segmentos demográficos biológicamente discernibles que se han perpetuado desde la colonia al siglo XX, donde existen los sectores: indio, mestizo y blanco. Agregando, además, que al sector indígena del siglo XV y XVI se le ha visto como sujetos sobrios, honrados, veraces y diligentes, pero que se fueron degenerando gradualmente por efectos de la coca, del alcohol y de la explotación ejercida sobre él por los conquistadores españoles. Y en el período colonial tardío y republicano se les ha visualizado como borrachos, perezosos, mentirosos, ladrones, arteros y abyectos (Fuenzalida et al. 1970). Situación que influenció en la ausencia de una ciudadanía efectiva. ra del Pacífico y la derrota peruana modifican completamente el territorio, y en este sentido, las disposiciones administrativas y jurídicas no fueron la excepción, pues se reorganiza el territorio, se nombran subdelegados y se instalan en las provincias de Arica y Tacna, un "Juzgado de Letras de Tacna" (Galdames 1981: 106). Estas disposiciones administrativas y jurídicas se aplican según las autoridades chilenas, al amparo que le otorga el tratado de Ancón, argumento discutido por Lima en los años posteriores al vencimiento del plazo establecido en el artículo $3^{\circ}$ del tratado. Sin embargo, desde una perspectiva jurídica, los ciudadanos peruanos del territorio hacen un uso copioso de dichos instrumentos jurídicos chilenos en los años posteriores a la firma del mencionado acuerdo (Ruz y Díaz 2011; Choque 2012; Díaz et al. 2013).

El Código Penal de 1874 establece como delitos todas aquellas acciones u omisiones voluntarias, es decir en crímenes, simples delitos y faltas ${ }^{10}$. Señalando además, en el artículo $45^{\circ}$, que la ley chilena es obligatoria para todos los habitantes de la república, incluidos los extranjeros; obligación que se materializa claramente en el juicio que realiza el gobernador de Arica, Luis Arteaga, contra el sacerdote peruano Vitaliano Berroa y Bernedo por las calumnias e injurias de las pinturas de Socoroma. En dicha causa participaron, en calidad de testigos del gobernador, Pedro Humire y Félix Carrasco ${ }^{11}$, pero en "confesión" re-

9 En el año 1880 se realizó la "conferencia de Arica" entre Chile, Perú y Bolivia, cuya mediación fue ejercida por los Estados Unidos. El fracaso de las negociones generó la prolongación del conflicto y el inicio del control del territorio en lo tributario, policial y judicial, mediante un Decreto emitido por el general Manuel Baquedano. Por ello, el recién creado Juzgado de Letras de Tacna debió atender las causas civiles del departamento. Además, se crearon los jueces de paz en los distritos rurales y se definió la continuación temporal de la justicia civil peruana, mientras que en lo criminal se aplicaron las leyes chilenas. Finalmente, el 31 de octubre de 1884, el gobierno de Chile, luego de la ratificación del tratado de Ancón, dictó la ley 2.261, que aplicó de manera definitiva el sistema judicial chileno, hecho que vino acompañado de la creación de nuevas unidades administrativas (subdelegaciones) según el decreto $\mathrm{N}^{\circ} 682$, donde sus primeras autoridades fueron militares chilenos y luego de indígenas como Teodoro Huanca de Putre (Choque 2012).

10 Ver artículo $3^{\circ}$ del Código Penal.

11 "Testigo" es aquella persona que presenció directamente o indirectamente la comisión de un delito, o bien posee antecedentes que pueden ayudar a esclarecer los hechos. 
ligiosa o "declaración conjunta", se desentendieron de su manifestación judicial, pues la habrían realizado bajo coacción de las autoridades ${ }^{12}$. En otro documento de la época pero de distinta índole ${ }^{13}$, el mismo sacerdote informa al obispado de Arequipa que el gobierno de Chile busca la expropiación de ciertos terrenos colindantes a la construcción del ferrocarril Arica-La Paz, solicitando a Monseñor Mariano Holguín Maldonado, obispo de Arequipa, la autorización para vender al gobierno dichos terrenos. Ambas situaciones evidencian el reconocimiento de la vigencia de la legislación chilena, esto a pesar de los conflictos políticos y judiciales (Figura 2).

Un caso similar se aprecia en el juicio sostenido por el inspector de distrito de Socoroma, Ramón Santalices, contra Serafín Humire en el año $1913^{14}$ por la sustracción de libros de clases de la escuela del pueblo ${ }^{15}$. Dicho pleito contó con numerosos testigos en favor del inspector $^{16}$, que luego se retractaron de sus declaraciones y favorecieron a Humire ${ }^{17}$. Aunque el querellante incurrió en el delito de calumnia por la imputación de una falsa infracción (hurto), los testigos ni el denunciante fueron sancionados por los tribunales de Arica. En otros casos, se muestra el rol delictivo de algunos vecinos de Socoroma y Putre, como la acusación de abuso de autoridad y estafa contra Diego Quiguayo ${ }^{18}$, denuncias por usurpación de funciones en contra de Antonio Mollo ${ }^{19}$ y de crímenes graves con connotación pública, tales como los casos de Domingo Humire o incesto en contra de José Gutiérrez $^{20}$. Igualmente, es posible identificar diversos procesos judiciales, motivados por las infracciones a la ley $\mathrm{N}^{\circ} 1.362$, llamada de "Reclutas y Reemplazos del Ejército y la Armada", donde los infractores fueron vecinos de las comunidades andinas, se logra identificar algunos nombres como Gregorio Mollo, Alfonso Aranda, Benedicto Mazuelos, Herminio Mollo, Lorenzo Apas y Pedro Huanca, entre otros ${ }^{21}$.

12 AJA, Legajo $\mathrm{N}^{\circ} 786$, expediente $\mathrm{N}^{\circ} 24$.

13 AJA, legajo $\mathrm{N}^{\circ} 30$, expediente $\mathrm{N}^{\circ} 381$, foja 490.

14 AJA, Legajo $\mathrm{N}^{\circ} 31$, expediente $\mathrm{N}^{\circ} 23$.

15 Acusación basada en el artículo $442^{\circ}$, "El robo en lugar no habitado, se castigará con presidio menor en sus grados medio a máximo". El hecho se agrava por ser un bien de uso público como los libros de clases (artículo $443^{\circ}$ ).

16 AJA, Legajo $\mathrm{N}^{\circ} 31$, expediente $\mathrm{N}^{\circ} 23,4 \mathrm{~V}$.

17 AJA, Legajo $\mathrm{N}^{\circ} 31$, expediente $\mathrm{N}^{\circ} 23,5,5 \mathrm{v}, 8 \mathrm{v}$ y 9 .

18 AJA, Legajo $\mathrm{N}^{\circ}$, expediente $\mathrm{N}^{\circ} 10$ y 11.

19 AJA, Legajo $\mathrm{N}^{\circ} 19$, expediente $\mathrm{N}^{\circ} 4$.

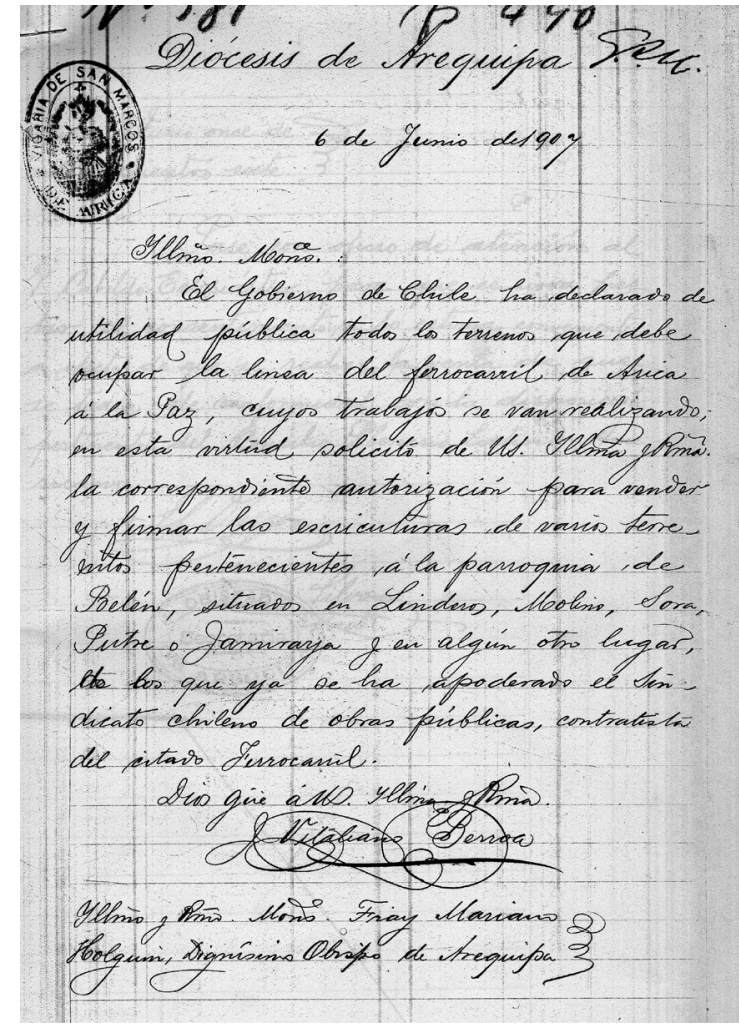

Figura 2. Carta de Vitaliano Berroa y Bernedo al Obispo de Arequipa (Fuente: AN, Conservador de Bienes Raíces de Arica, 1907).

En los casos descritos, la totalidad de los testigos, víctimas e infractores, fueron vecinos de las comunidades andinas, exceptuando el sacerdote, gobernador e inspector de distrito. Además, parte importante de las personas aludidas participan de los alegatos en los tribunales de la ciudad de Arica, y en casos excepcionales se hicieron representar por algún apoderado. Por tanto, cabe afirmar que los comuneros conocen el funcionamiento del sistema judicial chileno, lo que implica un reconocimiento efectivo de la institucionalidad jurídica vigente desde la firma del tratado de Ancón, sin tener presente las objeciones ideológicas de la época, lo cual conlleva a la aplicación del conjunto de normas jurídicas y principios del derecho por el Estado chileno, no incompatible con las pretensiones y posturas políticas de los campesinos, y que continuaran siendo partidarios de la causa perua-

20 AJA, Legajo $\mathrm{N}^{\circ} 31$, expediente $\mathrm{N}^{\circ} 17$ y Legajo 492, expediente $\mathrm{N}^{\circ} 1$. 21 AHVD, Oficios Recibidos, Comandancia General Arica, 1915 $1918, N^{\circ} 522$. 
na, como Juan de Dios Aranda y Antonio Mollo, siendo activos usuarios de los trámites notariales y del Conservador de Bienes Raíces de Arica. Una explicación a esta dicotomía la ofrecen Rodrigo Ruz y Alberto Díaz, pues para los autores, el efecto propagandístico "chilenizador" incentiva a los comuneros indígenas a inscribir sus propiedades bajo la legislación chilena de manera temprana (Ruz y Díaz 2011: 174), hecho que demuestra las reacciones individuales y colectivas en el uso de los procedimientos judiciales para las litigaciones, pues solo así se podría dar certidumbre jurídica sobre los bienes raíces e inmuebles a los comuneros proclives al Perú, mientras se alcanzaba un solución definitiva al conflicto por la soberanía del territorio (Basadre 1974; Melucci 1996, 1999; Ruz 2005) $)^{22}$. En consecuencia, los litigantes indígenas encontraron en las disposiciones chilenas y en el propio tratado de Ancón, un espacio de intermediación jurídica que les permitió la certidumbre legal a sus alegatos por tierras y causas civiles ${ }^{23}$, sin preocuparse de qué nación fuese la vencedora del litigio por las "provincias cautivas". Ello, producto de los tempranos procesos de interacción con los proyectos políticos y legales, que llevaron a cabo los gobiernos liberales en el Perú, permitiendo a los comuneros andinos apropiarse de la experiencia en jurisprudencia, para de esta forma enfrentarse judicialmente al Estado y a otros vecinos. Más tarde volcarían estos aprendizajes en contra de las autoridades chilenas, generando para ello nuevas estrategias legales, que son expresiones de un pensamiento "dualista" (Melucci 1996) 24 pues se definieron distintas estrategias y acciones frente a

22 Alberto Melucci, consideró que la identidad colectiva se define como una serie de atributos que comparten los individuos ya sea con características naturales, esenciales, psicológicas y rasgos regionales, siendo factores que permiten una permanente renegociación cultural, social y política.

23 La intermediación jurídica debe ser entendida como la canalización o comunicación entre sujetos o sociedades que establecen una relación jurídica ante una determinada controversia, no obstante, también puede ser denominadas como mediaciones o conciliaciones. La calidad de espacio deriva de las escenificaciones y los despliegues narrativos de los instrumentos jurídicos, que se despliegan entorno a estos lugares de valor simbólico y coercitivo.

24 Si bien el "pensamiento dualista" de Melluci, proviene del estudio de los movimientos sociales, este permite comprender la importancia de las estructuras sociales o el poder de las intenciones de los actores individuales o colectivos frente a determinados conflictos.

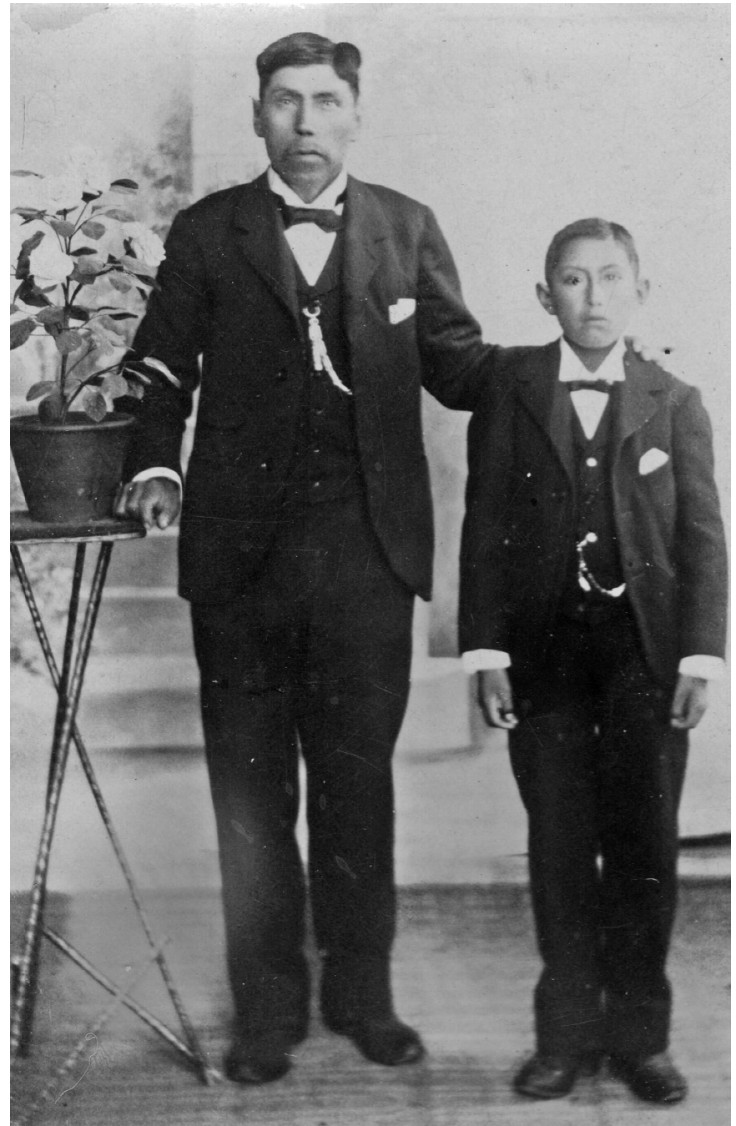

Figura 3. Antonio Mollo junto a su hijo Herminio en la ciudad de Lima (Fuente: Archivo de la Familia Mollo Aranda).

determinados peligros y que no serán advertidas oportunamente por la administración chilena (Figura 3).

\section{* Imaginarios morales y étnicos. Visiones COMUNITARIAS Y ESTATALES}

Para Benedict Anderson, los ciudadanos se asocian entre sí en un nivel imaginario, simbólico y práctico, aunque no tengan ninguna relación personal con los demás y luchen por intereses propios totalmente distintos (Díaz et al. 2010; Choque 2012). No obstante, esta especie de espíritu comunitario necesita concebirse, expresarse y hacerse tangible en la sociedad, pues los sujetos o sus agrupaciones deben compartir las líneas de parentesco, cultura y territorio, entre otros elementos y significados (Mauss 1969). Anderson también afirma que una comunidad imaginable se produce por la "existencia de una lengua sagrada y una escritura” (Anderson 2000: 31). En 
tales consideraciones epistemológicas, el ejercicio pleno de la ciudadanía y sus derechos poseen una lectura difusa y controversial en algunas regiones del Perú y Chile. No obstante, para el conflicto por la soberanía de Arica y Tacna, estas visiones fueron influenciadas por discusiones sobre la invención de la nación, la tradición y la identidad. Situación que permite el paso de una "ciudadanía simbólica" o "tributaria" a otra "política" ${ }^{25}$, donde los sujetos están altamente comprometidos con las causas nacionales (Choque 2013). Por ello, el Perú y Chile demandaron de sus "ciudadanos" un fuerte compromiso ideológico y práctico frente a la controversia por Arica y Tacna, amparándose en disposiciones administrativas y legales que se emitieron desde Santiago o Lima. Generando con ello una serie de calificativos positivos y negativos que incurrieron en interpretaciones morales y étnicas, según el compromiso ideológico de los "sujetos políticos" (Ruz et al. 2011), acto que también se expresa en los documentos judiciales.

Los estados latinoamericanos construyeron la idea del "indio permitido", un sujeto que está aprobado y validado por el gobierno, que acepta sin cuestionar las políticas del Estado, que las promueve, que no demanda más allá, y sobretodo es promovido como un modelo de imitación (Hale 2004) ${ }^{26}$. Coincidiendo con este planteamiento, Patricia Richards da cuenta que el "indio permitido": "abraza políticas integracionistas y participa sin cuestionar en programas de gobierno" (Richards 2010: 79). Y en la vereda opuesta está el "indio insurrecto", quien no desea compartir el proyecto hegemónico ni busca integrarse plenamente a la nación mestizocriolla ${ }^{27}$, ambos conceptos son parte del discurso producido por los agentes peruanos y chilenos.

Los documentos judiciales de los tribunales de Arica reflejan estas asignaciones valóricas y étnicas, que se convierten en estereotipos reconocibles y aceptables por la sociedad. Dicha situación queda de manifiesto en la declaración de doña Delfina Moscoso, dueña de un conventillo en Arica y que el 18 de Agosto del año 1913, tras la muerte de Domingo Humire, relata: "Ocupaba la pieza $\mathrm{N}^{\circ} 32$, doña Eulalia Garay, quien tuvo conocimiento con un joven, que cree boliviano (indio), sin que sepa la declarante como se llama este hombre"28, cabe señalar que, tanto Delfina y Eulalia, desconocen el apellido del occiso, pero tienen la certeza que se trababa de un "indio".
Un documento parroquial aportado tiempo después a la causa $\mathrm{N}^{\circ} 0086542$, certificó la calidad de indígena del finado, Domingo Humire ${ }^{29}$, diligencias posteriores y nuevas declaraciones solo ratificaron la condición étnica de Humire. No obstante, hacia el año 1919, la causa seguía abierta, pues de manera sucesiva se asignaron curadores de los bienes y dinero del finado ${ }^{30}$, que terminaron finalmente en los bolsillos de Julio Tapia Cousiño, quien luego fue enjuiciado por violar los artículos $452^{\circ}, 483^{\circ}$ y $481^{\circ}$ del Código Civil, notificado por el juzgado de Arica, que "dentro de segundo día constituya caución suficiente para cancelar (cautivar) como curador de la herencia de que se trata bajo apercibimiento legal" ${ }^{\prime 31}$, no existiendo datos posteriores, cabe suponer que la "indefensión jurídica" del occiso permite la apropiación de sus bienes. Igualmente, en el juicio de Ramón Santalices con Serafín Humire, las mismas asignaciones valóricas y étnicas se hicieron presentes, pues la profesora Amalia Herrera de Santalices testifica que el acusado es indigno de su amistad, y que sea declarado como su enemigo acérrimo en el pueblo de Socoroma, pues aconsejó a los demás padres de familia que no envíen a sus hijos a la escuela, ella afirma que Humire le "prometió hacerme salir del empleo i con ese fin fue donde el señor gobernador a decirlo que yo

25 En el siglo XIX, el Perú sigue inmerso en relaciones contradictorias con los ciudadanos de origen "indígena", esto debido a la articulación de las viejas formas de relación colonial, que permitieron la reinstauración la contribución indígena sobre los nuevos ciudadanos en 1826 y que se extendió hasta el año 1854 . Si bien, el Mariscal Catilla abolió dicha carga impositiva "por estar bañado [el tributo] en la sangre y las lágrimas de quienes lo pagan” (Contreras 2005: 86), este reapareció en 1856, 1866, 1872 y 1886, bajo los nombres de contribución "personal" o "jornal", que se aplicaron de manera sucesiva en el Perú y cuyos principales afectados fueron los indígenas. Solamente en 1895 el gobierno de Nicolás de Piérola, logra abolirlas de manera definitiva, por tanto, a lo largo de este siglo el indígena, tuvo más bien obligaciones fiscales y no derechos políticos. En las provincias del sur del Perú, será la guerra contra Bolivia en 1842, las guerras civiles, revoluciones y contrarrevoluciones, las que permitirán el acceso a una ciudadanía política más temprana en Arica y Tacna.

26 Hale, consideró además, que el "indio permitido" opera en un contexto neoliberal, donde los sujetos con raíces étnicas han pasado las pruebas de la modernidad y ha sustituido sus protestas con "propuesta", en un entorno adverso y de dominio del Estado nacional.

27 El "indio insurrecto", por otra parte es objeto de marginación y represión del Estado. 
había castigado cruelmente a sus hijos, lo cual ha jurado i promovido, eso es solo una calumnia infame la que me imputa ese indio"32. Los antecedentes y las declaraciones de numerosos testigos, que exculparon a Humire, permitieron al tribunal afirmar que no se encuentra acreditada la existencia del delito que ha servido de base al proceso, determinándose el sobreseimiento temporal del asunto hasta que se presenten mejores datos de investigación, conforme al artículo $439^{\circ}$, inciso 2 del Código de Procedimiento Penal.

Esta imagen de "indio insurrecto" fue representada por el "indio peruano", atribuyéndosele la posesión de una barbarie tétrica, ruin y enemiga de la civilización y los valores de la patria chilena, así la disputa ideológica y política por el territorio contribuye al afloramiento de un racismo y violencia creciente. Estos "sujetos políticos" son despojados de humanidad y toda violencia simbólica o directa, fue posible para ellos, pues para "los cholos no hay justicia" (Palacios 1974). Igualmente, predominaron los calificativos de "indiada" al referirse a la población local de las comunidades andinas. Hecho denunciado por el presbítero español Domingo Martínez Gago quien, siendo capellán de Putre y Socoroma, observa el nivel de violencia existente en contra de la población local, señalando que ha visto "atropellos más grandes e inimaginables, cada vez que los sufrían, los peruanos nativos [indígenas] venían a decírmelo [...] Yo les escuchaba y sentía temblar mis carnes de horror" (Palacios 1974: 218). En la década de 1924, Luis Barceló, integrante de la Comisión Plebiscitaria Chilena ${ }^{33}$, realiza una tipificación de los habitantes de la sierra de Arica, expresando que casi la totalidad de la "población de las subdelegaciones [...] de Putre, Belén y Codpa, del Departamento de Arica, esta constituidos por estos indios de raza aymara" (Díaz et al. 2010).

28 AJA, Legajo $\mathrm{N}^{\circ}$ 31, expediente $\mathrm{N}^{\circ}$ 17, f.4.

29 AJA, Legajo $\mathrm{N}^{\circ} 31$, expediente $\mathrm{N}^{\circ} 17, \mathrm{f} .7-7 \mathrm{v}$.

30 AJA, Legajo $\mathrm{N}^{\circ} 31$, expediente $\mathrm{N}^{\circ} 17$, f.13, 14v, 15 y $18 \mathrm{v}$.

31 AJA, Legajo $\mathrm{N}^{\circ} 31$, expediente $\mathrm{N}^{\circ} 17$, f.19.

32 AJA, Legajo $\mathrm{N}^{\circ} 31$, expediente $\mathrm{N}^{\circ} 23, \mathrm{f} .15$.

33 En 1925 el árbitro presidente Calvin Coolidge de los Estados Unidos, expide el fallo final y sostiene que el tratado de Ancón está vigente, que el plebiscito debe realizarse. Dando, inicio al periodo más intenso del conflicto político entre Perú y Chile, y a un aumento exponencial de la violencia en las provincias de Arica y Tacna
Contrariamente a estos juicios y estereotipos negativos, los "ciudadanos" de las comunidades andinas de Arica, se definieron a sí mismos, como "peruanos", frente a los alegatos jurídicos, no dejando intersticios o dudas sobre su ciudadanía (Choque 2013). Este temprano, reconocimiento de adscripción ciudadana y nacional, se debe en gran medida al temprano surgimiento de la escuela peruana en los territorios en la década de 1860 (Palacios 1974; Gambeta 2004; Choque 2012), pues se crearon escuelas en Codpa, Putre, Socoroma, Livilcar, Azapa y Lluta, sin perjuicio, que la élites indígenas llevaron a sus hijos a los colegios arequipeños (Choque 2012). Se agrega, a este reconocimiento, las distinciones de identidad como expresión social y cultural, teniendo un fuerte componente simbólico, con las antiguas formas de ser y memorias de los territorios de origen. Este tipo de afirmaciones, se vio reforzada por la propaganda peruana en Arica y Tacna, que convierte al "indio peruano" en un símbolo de identidad, entereza, resistencia, patriotismo e irredentismo, frente a la acción de los agentes y Estado chileno (Choque 2013). En consecuencia, las distinciones valóricas y étnicas, fueron construidas desde una perspectiva ideológica, donde la comunidad imaginada, tuvo rostros antagónicos y duales, las que son incluidas en las declaraciones y dictámenes judiciales según, el juicio y observancia del tribunal, que se remitió a reproducir los alegatos de chilenos, peruanos e indígenas.

\section{* Ethos cultural y praxis jurídica de la POBLACIÓN INDÍGENA}

El comportamiento cultural de la población indígena, se expresa como una construcción discursiva y valórica, enunciada de forma performatizada (Austin 1970), dependiendo de los contextos sociales, culturales y políticos. En este aspecto, Dominique Maingueneau (2002), considera al ethos como una enunciación, y que es parte de la construcción de la identidad, definiéndola como una corporalidad, presente en todo texto, oral o escrito, es decir, posee una expresión ética, que se enuncia según los símbolos y códigos distintivos, que exponen intereses individuales y colectivos, al momento de generar mecanismos de interacción sociocultural (White 1959). En tal sentido, las expresiones adaptativas, de las sociedades indígenas ante un nuevo poder hegemónico y sus prácticas jurídicas, se manifiestan tempranamente, pues a mediados de la década de 1540, los señores lupacas y más tarde, 
los principales de Hatun Carangas, ya se encontraban en pleitos con Lucas Martínez de Vegazo y los señores étnicos de la costa, por la recuperación de sus mittani o colonos ubicados en los valles de Arica (Trelles 1991; Hidalgo 2004; Choque 2009; Choque y Pizarro 2009)34.

El origen de estas interacciones, se producen pues los seres humanos recurren a patrones de comportamientos aprendidos, incorporándolos como herramientas, actividades o estrategias de su propia cultura. En este sentido, la idea de litigar constituye una práctica necesaria y obligatoria frente a los conflictos comunales o individuales, que se generalizaron en la medida que las influencias liberales se acrecentaron en los Andes y Socoroma (Jacobsen 1997; Aljovin de Losada 2005; Díaz et al. 2011; Méndez 2011). En este sentido, los pleitos de Bernabé Mena de Ticnamar con Francisco Vallesteros, natural de Codpa durante el año $1873^{35}$, por el no pago de plantas y cajones de alcohol ante los tribunales peruanos de la ciudad, se convierten en un ejemplo claro de la aplicación de los instrumentos jurídicos peruanos en los altos de Arica (Figura 4).

En igual sentido, un litigio sostenido entre los principales de Socoroma con Manuel Ventura, vecino de Putre en los tribunales de la misma ciudad, pero bajo la administración chilena, situación que evidencia la rápida adopción de las nuevas normas jurídicas e institucionalidad política establecida por el gobierno chileno. Este conflic-

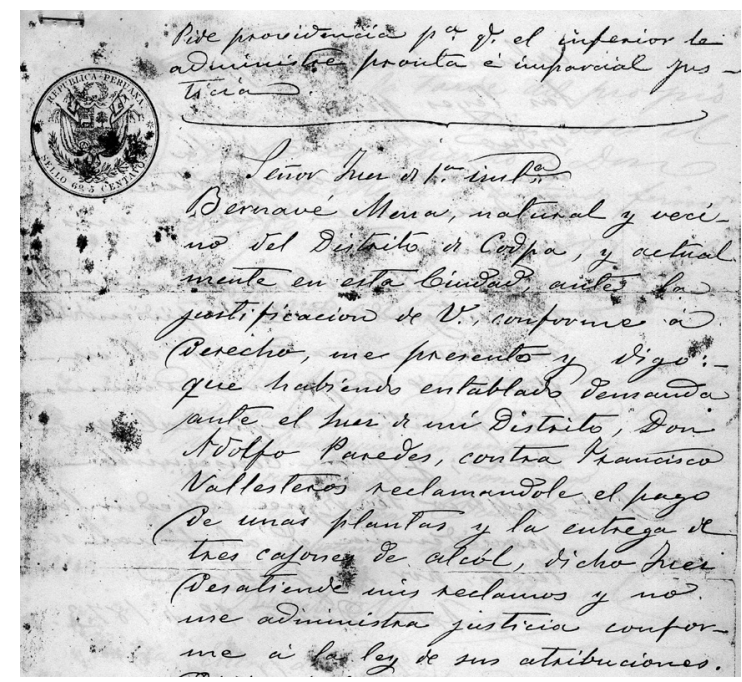

Figura 4. Carta de Bernabé Mena al tribunal de Arica, administración peruana (Fuente: Archivo Familia Mena). to se origina por la explotación indebida de los recursos comunales de Socoroma, por parte de Ventura, quien extrae y vende, la queñua (Polylepis tarapacana), a la mina de Choquelimpie. Los antecedentes jurídicos disponibles, informan que el "acusado", estuvo explotando los cerros de Socoroma sin el consentimiento de este pueblo, hecho que motiva la denuncia de parte de los vecinos ante los tribunales de Putre y más tarde en Arica. Los socoromeños sostuvieron que dichos cerros, pertenecían a sus territorios, como se desprende del siguiente texto:

\section{"[... Don Lorenzo Humire, don Marcelo Gutiérrez, don Doroteo} Humire, don Felipe bolaños, don José M. Humire i otros, todos vecinos de Socoroma, dicen que como miembros de la comunidad de Socoroma son dueños de los terrenos comprendidos; Por el sur, con la aguada de Copaquilla, Chusmisa, el cerro Copataya, por medio, i la quebrada de Viscachani. Camino parte para La Paz; Por el Este, con Pujullani, Ancochallguani i camino derecho de Parinacota, que viene a Socoroma; Por el norte, con el cerro Milagro, la quebrada de Nuñumani, desde su nacimiento i la (qu) majada de mismo nombre; Olvacaqui, la finca de don Doroteo Humire denominada, la pampa Urcuni i los cerros del pastal de Puquios; Por el Oeste, con los cerros del valle Lluta. Agregan los querellantes que el derecho de propiedad se los confieren las leyes peruanas, bajo cuyo imperio fueron creadas las comunidades de los diferentes pueblos del Departamento i de todo el Perú, i que dicho derecho los han heredado de sus antepasados, los que ejercían desde tiempos inmemorial, sin que jamás se les perturbara la tranquila posesión i dominio's6.

En dicho pleito, Ventura, arguye que dichos cerros, son fiscales o pertenecientes a la comunidad de Putre. No

34 La petición de la elite caranga esta consignada en AGI, Justicia, $\mathrm{N}^{\circ} 658$, f.590 y AGI, Charcas, $\mathrm{N}^{\circ} 49$.

35 Archivo personal de familia de Modesto Mena.

36 AJA, Judiciales Arica, $N^{\circ}$ 447, foja 314v, 1912.

37 En el año 1787, se realizó la demarcación de la Doctrina de Belén, la cual señala que Socoroma, además poseía tierras en el valle de Lluta, en áreas colindantes con los anexos (comunidades) de Sora y Churiña (actualmente llamada Molinos). Según el presbítero Don Mariano Pacheco de Peñaloza, quien menciona que en Sora"[...] ay un ayllo solo de tributarios que se componen el número de veinte y ocho entre casados, viudos y solteras. Se ha de advertir que en las tierras del dicho valle tienen la misma parte de tierras de repartimiento las dos comunidades de indios de Socoroma y de Putre y siembras las mismas especies que los demás. AAA, Vicaria Arica, Belén, Legajo único, 1787. 
obstante, los querellantes presentan un cuaderno de actas del año 1793, demostrando que dichos terrenos pertenecen a la comunidad de Socoroma (Figura 5) ${ }^{37}$. Movilizando a los tribunales de Arica, alrededor de treinta testigos que conocían los linderos de la comunidad, quienes a su vez acusaron al querellado de cortar grandes cantidades de queñua. Los descargos de Ventura, se sustentaron en afirmar que dichos documentos eran falsos. El juez Rodríguez Rosas, dentro de las deliberaciones, consideró primero, que estos territorios estaban bajo el espíritu del tratado de Ancón, no modificando el modo de ser y la organización social, que existió previamente en el territorio y que fueron validadas por las leyes peruanas, aduciendo en su fallo que: "El gobierno del Perú dio a cada comunidad el usufructuó de los respectivos terrenos, cree el fiscal que las comunidades tienen actualmente derecho a usufructuar los terrenos que están dentro de sus propios límites, quedando al juzgado el resolver si los terrenos de donde el querellado saca la leña forman o no parte de la comunidad de Socoroma" ${ }^{\prime 38}$.

La sentencia del juez, establece el amparo presentado por los socoromeños por la posesión de los terrenos pertenecientes a la comunidad, condenándose a Manuel Ventura a "pagar por los perjuicios causados a los querellantes i costas de la querella i se le apercibe para que se abstenga de cortar leña de los terrenos de la comunidad expresada" ${ }^{\prime 39}$. Este caso, ejemplifica la continuidad del ethos cultural en Socoroma, ya que evidencia como el uso de la memoria colectiva y los despliegues narrativos sobre la posesión y utilidad de los espacios comunales, se mantuvieron vigentes (Figura 6). Además, la existencia de información documental del siglo XVIII, tuvo un rol fundamental en el pleito contra Ventura, porque vino a validar las declaraciones de los testigos, que inicialmente fueron coaccionados por el tribunal de primera instancia, el juez de la $4^{\circ}$ Subdelegación de Putre, quien favorecía al querellado. Este fenómeno, fue descrito tempranamente por Émile Durkheim (1999), como una regularidad es-

38 AJA, Judiciales Arica, $\mathrm{N}^{\circ} 447$, foja $315 \mathrm{v}$.

39 Ídem.

40 Las prácticas que engendran distintas configuraciones sistemáticas de propiedades que expresan las diferencias objetivamente inscritas en las condiciones de existencia bajo la forma de sistemas de variaciones diferenciales que permiten descubrir, interpretar y evaluar estilos de vida, según Pierre Bourdieu (2000).

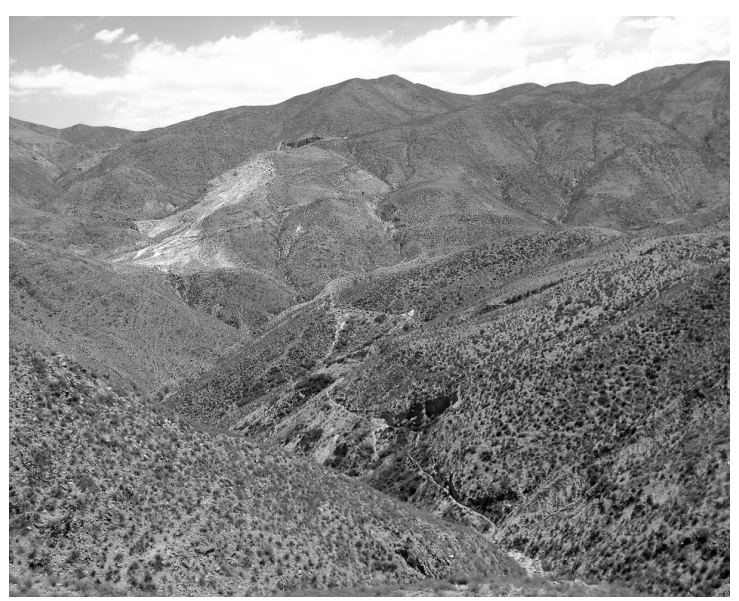

Figura 5. Zona contigua al área en litigio entre los vecinos de Socoroma y Manuel Ventura, borde del Canal de Aroma (Fuente: Elías Muñoz, 2014).

tructural, que se manifiesta por la acción de las normas de orden social y que las comunidades andinas incorporaron a sus protocolos y actuaciones cotidianas (Rivera 2008).

La existencia de los comportamientos culturales, llevaron a nuevos significados y valores, implicando "nuevas prácticas y relaciones sociales" (Williams 1980: 145). En igual sentido, Bourdieu, considera que este tipo de prácticas se producen en planos individuales y colectivos, adquiriendo diversas expresiones, dependiendo de las estructuras y códigos simbólicos existentes (Bourdieu $1995)^{40}$. Dicha situación permite comprender como se manifestaron los procesos adaptativos de la población andina, luego del término de la guerra del Pacífico, pues dichos sujetos políticos (Díaz et al. 2011), no dudaron en acatar el uso de las normas jurídicas de la nación vencedora. Entonces, dichos actos son una expresión de la praxis jurídica del andino, pues utilizo a su beneficio, el sistema jurídico colonial, el republicano peruano y luego el chileno. Esta actuación, pragmática e instrumental no equivale a colocar elementos coyunturales o ideológicos como un tema central, sino que solo se ampara en el uso y goce del derecho, que posee un rol significativo y de significado para las comunidades andinas. Desde esta perspectiva, se observa una conjunción de la praxis política y jurídica, pues se actúa en base a la legitimidad que le entregan los sistemas normativos (Rodríguez-Iturbe 2011), cuya compresión y apropiación, solo se logra en la medida que los comuneros andinos, hacen un uso instrumental 


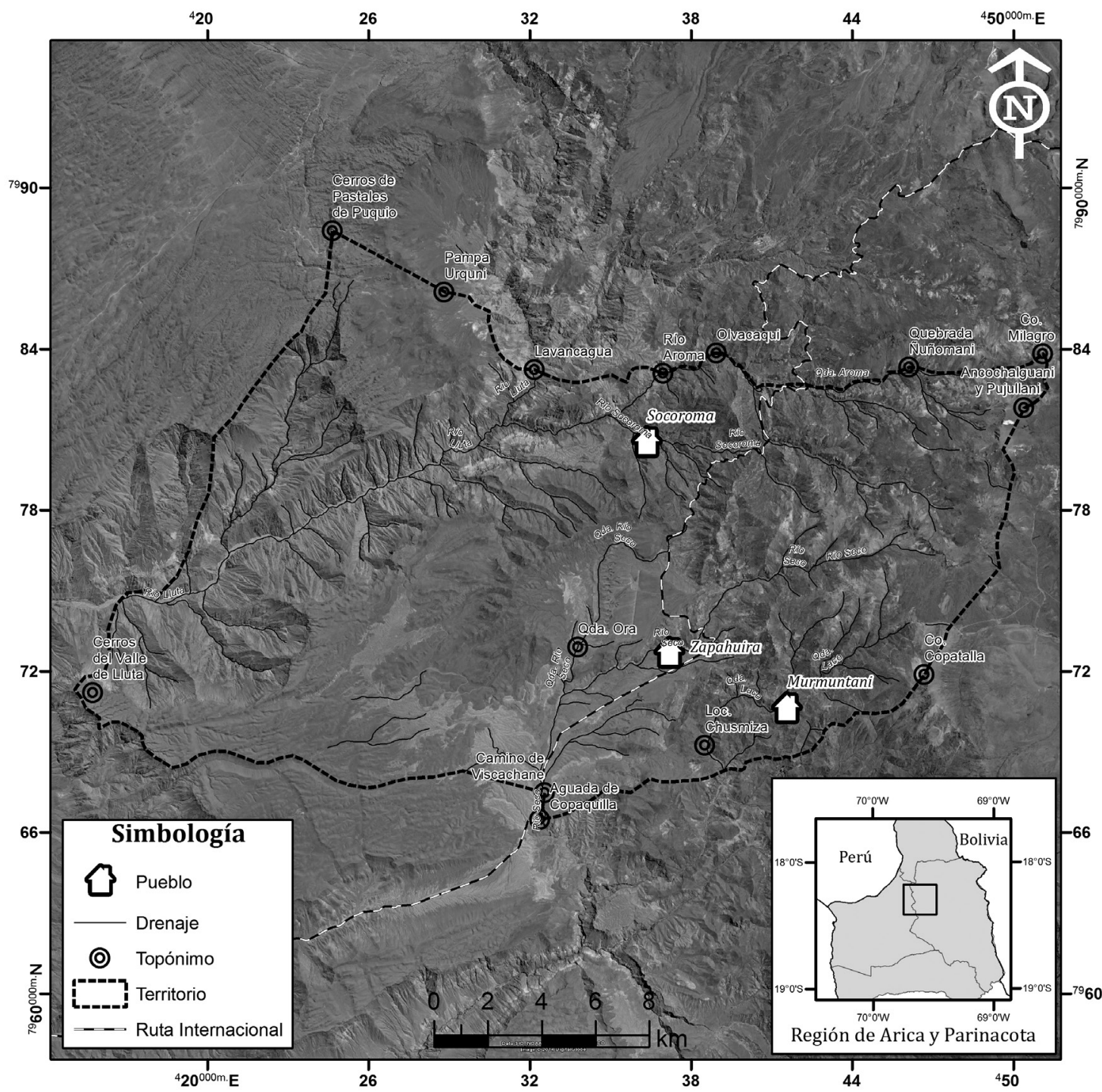

Figura 6. Extensión aproximada del territorio de Socoroma, según el juicio entre el pueblo de Socoroma y Manuel Ventura (Fuente: AN, Judiciales Arica, $\mathrm{N}^{\circ} 447,1912$ ).

del derecho, situación que revela el ejercicio de un humanismo jurídico y político, es decir, la existencia de una conciencia ciudadana y una racionalidad política, como sugiere Thomas Hobbes, al hablar de la naturaleza política del hombre. En consecuencia, los pobladores andinos, no solo fueron actores políticos claves para Chile y Perú respectivamente, sino también, propulsores de sus propias agendas políticas, donde lo jurídico tuvo un rol funcional y cuya articulación devela el éxito de los principios del liberalismo político en los
Andes desde mediados del siglo XIX en adelante.

\section{* Reflexiones finales}

A lo largo del siglo XIX, los comuneros andinos transitaron desde una "ciudadanía tributaria" a una "ciudadanía política" (Díaz et al. 2011), hecho que les permitió ir construyendo una ciudadanía impregnada con los ethos culturales, que facilitaron un actuar político colectivo como se expresa en Socoroma, demandando además, el 
uso de instrumentos jurídicos que convergieron con las memorias individuales y colectivas, revitalizando así la vigencia de las antiguas formas de representación y de poder local. Igualmente, se demuestra que los litigantes ajenos a la comunidad optaron, por querellarse contra sujetos o individuos y no contra una unidad corporativa, como lo era la comunidad, pues esta podía movilizar todos los recursos disponibles ante los tribunales. De la misma forma, el enfrentamiento de la élite indígena con agentes gubernamentales chilenos en los pleitos de Socoroma, evidenciaron que los vecinos, que testificaron en contra Humire, cambiaron sus testimonios favoreciendo al querellado o simplemente expresaron que fueron coaccionados por el juez de la subdelegación de Putre. Las motivaciones de cambiar dichas declaraciones, se fundamentan en la necesidad de conservar la paz social y cultural de la comunidad, pues en distintos momentos, el querellado y los testigos convergen en los espacios rituales y sagrados de la comunidad (Choque 2013).

La construcción del "otro" desde las autoridades civiles y la propia comunidad dejan de manifiesto, como los conflictos ideológicos toman un cariz étnico, pues el origen indígena implica la subalternidad, no obstante desde la praxis jurídica, dicha condición no parece haber influenciado de manera significativa la actuación del Juzgado de Letras de Arica, a diferencia de lo que ocurría con los jueces de las subdelegaciones rurales, que actuaban más bien con criterios políticos y no jurídicos. En tal sentido, el ejercicio de la ciudadanía y el especial estatus jurídico de la provincia, facilita que los habitantes andinos pudieran circular en los tribunales ariqueños, sin las complejidades que se manifestaron en otras regiones de Chile o Perú.

La existencia de conflictos sociales, políticos y económicos, permite la consolidación de los ideales del libe- ralismo en los pobladores andinos, pues en la medida que trascurre el período de ocupación de Arica y Tacna (1883-1929), los ciudadanos andinos; primero, debieron adoptar una posición respecto de los conflictos, por la soberanía del territorio y; segundo, hicieron valer su condición de ciudadanos para reclamar sus derechos sobre los recursos comunales o heredados. Así como, la inscripción de títulos en el Conservador de Bienes Raíces o realizando juicios en contra de terceros por los bienes perdidos, calumnias o estafas, dando paso al quiebre final de las relaciones, obligaciones y cohesión comunal, que en Socoroma se evidencia en la década de 1950. Pues fue en esta década que la élite indígena sobreviviente, del litigio por Arica y Tacna, emigra por la perpetuación de la violencia o influenciada por los cambios culturales y el surgimiento de nuevas oportunidades económicas y políticas, que les ofrecen las ciudades costeras del norte de Chile y sur del Perú, siendo entonces, reemplazados por "escaladores sociales" o nuevos liderazgos campesinos, que surgen al amparo de las leyes chilenas, ejerciendo roles de subdelegados, inspectores de distrito, profesores y jueces de paz, quienes iniciaron su aparición durante los años del conflicto diplomático por las provincias cautivas de Chile y Perú.

Agradecimientos Este trabajo ha sido elaborado en el marco de los proyectos Fondecyt $\mathrm{N}^{\circ} 1140159$, UTAMAYOR N ${ }^{\circ}$ 5732-13 y el Convenio de Desempeño Universidad de Tarapacá-Mineduc. Además, agradezco a un grupo de colegas y evaluadores por sus comentarios y sugerencias que permitieron mejorar el presente artículo. Expresar mi gratitud al geógrafo Alan Rodríguez Valdivia. Asimismo, reconozco la labor de apoyo y asistencia de los funcionarios del Archivo Nacional de Chile y el Archivo Histórico Vicente Dagnino de la Universidad de Tarapacá, que colaboraron en la búsqueda de las fuentes documentales utilizadas. 


\section{* Referencias Citadas}

ANDERSON, B. 1993. Comunidades imaginadas. Reflexiones sobre el origen y difusión del nacionalismo. Fondo de Cultura Económica, Ciudad de México.

AUSTIN, J. 1970. Quand dire c'est faire. Éditions du Seuil, París.

BASADRE, J. 1974. Los conflictos de pasiones y de intereses en Tacna y Arica (1922-1929). Historia y cultura 8: 5-68.

BOURDIEU, P. y L. WACQUANT. 1995. Respuestas por una Antropología Reflexiva. Grijalbo, Ciudad de México.

BOURDIEU, P. 2000. La Distinción. Criterio y bases sociales del gusto. Taurus, Madrid.

CASTRO, L. 2008. El Estado chileno, los agentes fiscales y el temprano ordenamiento administrativo del espacio andino de la provincia de Tarapacá (1880-1930). Chungara. Revista de Antropología Chilena 40 (2): 219-233.

CASTRO, L. y N. RIVERA. 2011. La sociedad rural del oasis de Pica frente al proceso chilenizador: conflictos, interacciones y reacomodos (Tarapacá, norte de Chile 1880-1900). Estudios Ibero-Americanos 37 (2): 271-300.

CAVAGNARO, L. 1988. Materiales para la historia de Tacna, Tomo 2: Dominación hispánica, siglo XVI. Cooperativa San Pedro de Tacna, Tacna.

CONTRERAS, C. 2005. El impuesto de la contribución personal en el Perú del siglo XIX. Histórica, Vol. XXIX (2): 67-106.

CHOQUE, C. 2009. Memoria y olvido del pueblo de Socoroma. Gobierno Regional de Arica y Parinacota, Centro de Investigación de las Artes y Cultura de los Pueblos Originarios (CIACPO) y Centro de Estudios e Investigación Tierra viva, Arica.

2012. Se van los peruanos... los más testarudos se quedan: la memoria y olvido de la chilenización en el pueblo de Socoroma. Tesis doctoral, Pontificia Universidad Católica del Perú, Lima.

2013. Modesto Mena. Un plebiscitario irreductible de Ticnamar. Corporación Nacional de Desarrollo Indígena (CONADI), Arica.

CHOQUE, C.y E. PIZARRO. 2009. El Colesuyu Meridional: Espacio de articulación económica y cultural hispano-indígena en la segunda mitad del siglo XVI. Allpanchis 73-74: 241-267.
DÍAZ, A. 2003. Problemas y perspectivas socio históricas en el norte chileno: Análisis sobre la "Chilenización" de Tacna y Arica. Si somos Americanos V (4):373-393.

2004. Orden, patria y delincuencia en el desierto chileno. Un estudio cuantitativo sobre la intendencia de Tacna (18831926). Revista Historia de América 134.

DÍAZ, A., L. GALDAMES y R. RUZ. 2010. Nación e identidades en los Andes. Universidad de Tarapacá, Arica.

DÍAZ, A., R. RUZ y L. GALDAMES. 2011. Participación de la Población indígena de Arica y Tarapacá en la Política y la justicia comunitarias durante el siglo XIX. Revista de Estudios HistóricoJurídicos XXXIII: 511-533.

2013. En los intersticios de la chilenidad: Antonio Mollo y las identidades en conflicto en los Andes. Chungara. Revista de Antropología Chilena 45 (3): 473-492.

DÍAZ, A. y M. TAPIA. 2013. Los aymaras del norte de Chile entre los siglos XIX y XX: Un recuento histórico. Atenea 507: 181196.

DURKHEIM, E. 1999. Las reglas del método sociológico. Folio, Barcelona.

FUENZALIDA, F., E. MAYER, G. ESCOBAR, F. BOURRICAUD y J. MATOS. 1970. El indio y el poder en el Perú. Instituto de Estudios Peruanos, Moncloa-Campodónico Editores, Lima.

GALDAMES, L. 1981. Historia de Arica. Editorial Renacimiento, Santiago de Chile.

GAMBETA, F. 2001. Nueva crónica del tiempo viejo. Historia de Tacna, 1866-1924. Caja de Ahorro y Crédito de Tacna S. A. (CACT), T acna.

HALE, C. 2004. Rethinking Indigenous Politics in the Era of the 'Indio Permitido'. Nacla 1: 16-21.

HIDALGO, J. 2004. Historia Andina en Chile. Editorial Universitaria, Santiago de Chile.

INOSTROZA, X. 2011. Dimensiones del liderazgo étnico en el pueblo de Belén: Francisco Ocharan, secretario del cabildo indígena: Altos de Arica (1750-1813). Estudios Atacameños 46: $109-126$. 
JACOBSEN, N. 1997. "Liberalism and indian communities in Peru, 1821-1920". En Liberals, the Church and Indian Peasants. Corporate Lands and the Challenge of Reform in Nineteenth-Century Spanish America, R. Jackson (Ed.). University of New Mexico Press, Alburquerque.

MAINGUENEAU, D. 2002. Problèmesd'ethos. Pratiques 113/114: 55-68.

MAUSS, M. 1969. La nation. Ed. Ceuvres, París.

MENDEZ, C. 2011. De indio a serrano: Nociones de raza y geografía en el Perú (siglos XVIII-XXI). Histórica XXXV (1): 53-102.

MELUCCI, A. 1996. Challenging Codes. Collective Action in the Information Age. Cambridge University Press, Cambridge.

1999. Acción colectiva, vida cotidiana y democracia. El Colegio de México, ciudad de México.

MILLONES, L. 2004. Ser indio en el Perú: la fuerza del pasado. Las poblaciones indígenas del Perú (costa y sierra). Instituto Di Tella y Siglo Veintiuno Editores, Buenos Aires.

MUMFORD, J. 2008. Litigation as Ethnography in SixteenthCentury Peru: Polo de Ondegardo and the Mitimaes. Hispanic American Historical Review 88 (1): 5-40.

RIVERA, F. 2008. Topografía de los cronopaisajes - identidades sociales, prácticas culturales y "trama» histórica. Universitas humanística 65: 281-327.

RODRÍGUEZ-ITURBE, J. 2011. Praxis política y praxis jurídica. La ideologización y la justicia. Notas introductorias sobre el uso alternativo del derecho. Díkaion 20 (1): 11-47.

RICHARDS, P. 2010. Of Indians and Terrorists: How the State and Local Elites Construct the Mapuche in Neoliberal Multicultural Chile. Journal of Latin American Studies 42: 59-90.

RUZ, R. 2005. Escrituras, olvido y memoria. Títulos de propiedad, olvido y prácticas en la tierra aymara. Tarapacá. Siglos XIX/XX. Diálogo Andino 26: 91-107.

2008. Uso de pastales y construcción de circunscripciones comunitarias en la precordillera de Arica. Siglos XIX y XX. Diálogo Andino 31: 47-65.
RUZ, R. y A. DÍAZ. 2011. Estado chileno y comunidad indígena. Presión y conflicto sobre tierras de uso colectivo en el espacio precordillerano de Arica: Putre 1880-1935. Estudios Atacameños. Revista de Antropología Chilena 42: 173-188.

TATEISHI, H. 2008. La Constitución de Cádiz de 1812 y los conceptos de Nación/Ciudadano. Junta de Andalucía. En http://www.juntadeandalucia.es/educacion/vscripts/w bcc1812/w/rec/4038.pdf

TRELlES, E. 1991. Lucas Martínez Vegazo: Funcionamiento de una encomienda peruana inicial. Pontificia Universidad Católica del Perú, Lima.

UGARTE DEL PINO, J. 1978. Historia de las Constituciones del Perú. Editorial Andina, Lima.

WESTERMEYER, F. 2012. "Chile y la Constitución de Cádiz: Un primer acercamiento a una relación preterida". En Cuando las cortes de Cádiz. Panorama jurídico 1812, L. Marti (Ed.) UNAM, Ciudad de México.

WHITE, L. 1982. La ciencia de la cultura. Un estudio sobre el hombre y la civilización. Editorial Paidos, Barcelona.

WILLIAMS, R. 1980. Marxismo y Literatura. Península, Barcelona.

YEPES, E. 1999. Un plebiscito imposible: Tacna y Arica, 1925-1926. Ediciones Análisis, Lima.

\section{Fuentes inéditas}

Archivo Nacional de Chile, Santiago

Archivo Judicial de Arica (AJA), Legajos números 4, 19, 30, 31, 447 y 786.

Universidad de Tarapacá, Arica

Archivo Histórico Vicente Dagnino (AHVD), "Oficios Recibidos, Comandancia General Arica, 1915 - 1918".

Archivo General de Indias, Sevilla

Archivo General de Indias (AGI), Justicia, No 658

Archivo General de Indias (AGI), Charcas, $\mathrm{N}^{\circ} 49$.

Archivo Arzobispal de Arequipa

Archivo Arzobispal de Arequipa (AAA), Vicaria Arica, Belén, Legajo único, 1787.

Archivo Personal de Familia de Modesto Mena

Correspondencia y documentos Judiciales de Bernabé Mena. 